\title{
Clinical Manifestation and Complications of Scrub Typhus Cases: A Hospital-based Observational Study from Rural Part of West Bengal
}

\author{
Kalyan Sarkar ${ }^{1}$, Amitava Acharyya ${ }^{2}$, Susmita Ghosh ${ }^{3}$, Manas Ghosh ${ }^{1}$, Ambarish Bhattacharya ${ }^{4}$, \\ Kaushik Ghosh ${ }^{1, *}$
}

\section{Kalyan Sarkar ${ }^{1}$, Amitava Acharyya², Susmita Ghosh ${ }^{3}$, Manas Ghosh 1 , Ambarish Bhattacharya ${ }^{4}$, Kaushik Ghosh $^{1, *}$ \\ 'Department of Medicine, Murshidabad Medical College, Berhampore, Murshidabad, West Bengal, INDIA. \\ ${ }^{2}$ Central Sector Scheme of Grant-in-Aid for Promotion of Ayush Intervention in PHI-Ministry of AYUSH (Govt of India), New Delhi, INDIA. \\ ${ }^{3}$ Department of Anaesthesiology, Murshidabad Medical College, Berhampore, Murshidabad, West Bengal, INDIA. \\ ${ }^{4}$ Department of Medicine and Critical Care Nightingle and Monmohini Hospital, Kolkata, West Bengal, INDIA.}

\section{Correspondence}

Dr. Kaushik Ghosh,

Department of Medicine, Murshidabad Medical College, Berhampore,

Murshidabad, West Bengal, INDIA.

Mobile no: +919547901343

Email: drkaushikghosh@gmail.com

History

- Submission Date: 29-06-2020

- Revised Date: 25-08-2020

- Accepted Date: 30-10-2020

DOI : 10.5530/ijmedph.2020.4.39

Article Available online

http://www.ijmedph.org/v10/i4

\section{Copyright}

(C) 2020 Phcog.Net. This is an openaccess article distributed under the terms of the Creative Commons Attribution 4.0 International license.

\begin{abstract}
Introduction: Scrub typhus is very common re-emerging Rickettsia infection in India and many other South East Asian countries. The unplanned urbanization, deforestation and easy transportation leads to changes of place of occurrence of scrub typhus from hilly and forest terrains to plan land with different clinical manifestation. Aim: This study was conducted to identify the regional characteristic of clinical sign, symptom and treatment outcome of scrub typhus patients admitted in a tertiary level hospital of Murshidabad district of West Bengal. Methods: An observational cross sectional study was conducted among 82 hospitalized scrub typhus patients during September, 2019 to March, 2020. Patients were selected by purposive sampling procedure. Data were analyzed in descriptive statistic. Results: All study participants presented with acute febrile illness with other symptoms like headache, cough, dyspnea, nausea, generalized weakness, abdominal pain and myalgia. On examination, patients had hepatosplenomegaly (21\%), Iymphadenopathy (7\%), pedal edema (14\%), Icterus (12\%) and eschar (4\%). On investigation, elevated ALT (37\%), elevated AST (36\%), Low platelet count (25\%), low Hb\% (52\%), elevated WBC count (37\%) levels were the most common findings. Interestingly few patients diagnosed with co-morbid infections eg: enteric fever (12\%), Urinary tract infection (12\%), respiratory tract infection (27\%), dengue fever $(5 \%)$ and malaria (2\%). Low mortality rate $(4 \%)$ was observed due to tertiary level health care services and increased awareness among local medical fraternities on scrub typhus apart from lower virulence or indigenous resistance as host or environment factor. Conclusion: Scrub typhus is an important zoonotic disease of variable presentation with low fatality if diagnosed and treated early. It is necessary to include scrub typhus serology test as routine blood test for all acute febrile illness patients for this area.
\end{abstract}

Key words: Scrub typhus, Complications, Observational Study, Murshidabad.

\section{INTRODUCTION}

Scrub typhus is a zoonotic infectious disease caused by an intracellular parasite Orientia tsutsugamushi, a Gram-negative proteobacterium of family Rickettsiaceae, first identified in Japan in $1899 .{ }^{1}$ Humans are accidental host after exposed with chigger mite infested rural or semi urban fields particularly crop fields. It was considered a deadly disease in pre antibiotics era where as they have been brought under control in most of developed Asian nations.

In India, scrub typhus broke out in an epidemic form in Assam and West Bengal during the Second World War. Gradually, the disease became prevalent in many parts of India. In recent time, scrub typhus has re-emerged to become the major cause of Acute Febrile illness (AFI) in many parts of India (Shivalik ranges from Kashmir to Assam, Eastern and Western Ghats and the Vindhyachal and Satpura ranges in the central part of India) with myriad clinical presentation. ${ }^{2}$ Recently Bihar witness a massive scrub typhus outbreak as most common cause of Acute Encephalytic Syndrome on 2018. ${ }^{3}$ Himachal Pradesh, Sikkim and Darjeeling (West Bengal) also witnessed scrub typhus outbreak during 2003-2004 and 2007. ${ }^{2}$ In a study published from Rajasthan, authors noted scrub typhus as an emergent cause of acute renal failure. ${ }^{4}$

In this study area, we witnessed surge of dengue fever which is the most common cause of AFI in couple of decades. Further we also experienced sudden increases of scrub typhus cases which may mimic with dengue fever and other acute febrile illnesses in this area. However, officially there is no declaration from state government on this sudden increase of scrub typhus cases as 'scrub typhus outbreak' of this area. Present study have been carried out to document clinical features and complications including mortality and co-morbid 
disorders among diagnosed scrub typhus patients who were admitted in Monmohini Multi-specialty Hospital, Murshidabad hospital during September 2019 to February 2020. This study may provide information regarding regional variability of presenting clinical pattern of scrub typhus patients in this area.

\section{Methodology}

A cross sectional descriptive observational study was conducted among admitted scrub typhus patients at Monmohini Multi-specialty Hospital, Murshidabad during September 2019 to March 2020. All clinically suspected cases with acute febrile illness were investigated for malaria, dengue, scrub typhus, HIV-AIDS, HCV, Urinary tract infection (UTI), respiratory tract infection (LRTI/URTI), Pulmonary tuberculosis (PTB) and leptospirosis on admission. After establishing the cause of fever, total 82 scrub typhus IgM serology positive patients were included in this study. The related socio-demographic data were collected during admission procedure. The data related with clinical findings, laboratory reports, vital signs, treatment outcome of each patient were collected from patient bed head ticket from record section of the hospital.

Basic laboratory evaluation included complete blood count (CBC), peripheral blood smear, liver and renal function tests and chest X-ray were carried out of each patients. Other tests such as cerebrospinal fluid analysis, magnetic resonance imaging brain were performed as indicated. A diagnosis of scrub typhus was confirmed when a patient with an AFI had a positive serology for scrub typhus. ${ }^{4}$ Patients were included by purposive sampling procedure.

All patients were treated with empirical antibiotic (Injection Ceftriaxone) and symptomatic treatment medicines. After confirmation of diagnosis, the doxycycline was administered with other antibiotics as indicated to deal with other co-morbidities.

Data were analyzed by SPSS (IBM) software. Only descriptive statistic was performed in data analysis. The permission of the study was obtained from Institution Ethical Review Committee and informed consent was obtained from the patients.

\section{RESULTS}

A total 82 scrub typhus patients were included in this study. Majority of patients were literate (98\%), female (54\%) and belongs to $21-49$ age group (55\%). Regarding occupation, 34\%, 23\%, $18 \%$ subjects were housewife, student and serviceman respectively (Table 1).

The most common clinical presentation on admission were fever (100\%), generalized weakness $(54 \%)$, abdominal pain $(39 \%)$, headache $(37 \%)$ and nausea (48\%). Other notified clinical symptoms were breathlessness, cough, altered sensorium, myalgia, upper lid oedema, rashes, hemoptysis and decreased Urine output. (Table 2) The common clinical sign were hepatosplenomghaly $(21 \%)$, pedal oedema (14\%), Icterus $(12 \%)$ and hypotension /shock (11\%) etc. Eschar (Figure 1) and lymphadenopathy were found among $4 \%$ and $7 \%$ cases respectively (Table 3 ).

Among all patients, anemia $(\mathrm{Hb}<11 \mathrm{gm} / \mathrm{dl}), \mathrm{WBC}$ count $<4000 /$ cumm, WBC count $>11000 /$ cumm, plural effusion and elevated ALT found among 52\%, 05\%, 37\%, 20\% and 37\% persons respectively. Interestingly few patients diagnosed with co-morbid infections eg: enteric fever (12\%), Urinary tract infection (12\%), respiratory tract infection (27\%), dengue fever (5\%) and malaria (2\%). No any patient found with co-morbid infection with HIV-AIDS, hepatitis, HCV and leptospirosis infections. 21 (25\%) patient's platelet count dropped below 1 lakh/cumm (Table 4). The maximum patients stayed in the hospital for treatment was 1-4 days (56\%) and only $29 \%$ patients required ICU treatment. Only twelve (15\%) patients required ventilation support. $3(4 \%)$ patients' required hemo-
Table 1: Distribution of socio-demographic variables of scrub typhus patients ( $\mathrm{n:}$ 82)

$\begin{array}{cc}\text { Variables } & \mathbf{n}(\%) \\ \text { Age (years) Mean : 38.35 } & \\ \leq 20 \text { years } & 15(18) \\ 21-49 \text { years } & 45(55) \\ 50 \geq \text { years } & 22(27) \\ \text { Gender } & \\ \text { Male } & 38(46) \\ \text { Female } & 44(54) \\ \text { Literacy } & \\ \text { Literate } & 80(98) \\ \text { Illiterate } & 02(2) \\ \text { Occupation } & \\ \text { Student } & 19(23) \\ \text { House wife } & 28(34) \\ \text { Service } & 15(18) \\ \text { Business } & 12(14) \\ \text { Retired } & 08(11)\end{array}$

Table 2: Distribution of clinical symptoms of scrub typhus patients on admission ( $\mathrm{n:} \mathrm{82)}$

\begin{tabular}{ccc}
\hline Symptoms & $\mathbf{n}$ & Percentage \\
Fever & 82 & 100 \\
Breathlessness & 25 & 30 \\
Decreased Urine output & 04 & 05 \\
Altered sensorium & 13 & 16 \\
Rash & 04 & 05 \\
Nausea & 40 & 48 \\
Myalgia & 13 & 16 \\
Cough & 23 & 29 \\
Headache & 31 & 37 \\
Haemoptysis & 03 & 04 \\
Generalized weakness & 44 & 54 \\
Abdominal pain & 33 & 39 \\
Upper lid oedema & 07 & 09
\end{tabular}

Table 3: Distribution of clinical signs of scrub typhus patients on admission ( $\mathbf{n}: \mathbf{8 2}$ )

$\begin{array}{ccc}\text { Signs } & \mathbf{n} & \text { Percentage } \\ \text { Eschar } & 03 & 04 \\ \text { Icterus } & 10 & 12 \\ \text { Lymphadenopathy } & 06 & 07 \\ \text { Pedal oedema } & 12 & 14 \\ \text { Hypotension/shock } & 09 & 11 \\ \text { Hepatospleomegaly } & 18 & 21\end{array}$


Table 5: Distribution of treatment and treatment outcome related variables of scrub typhus patients (n: 82 )

\begin{tabular}{|c|c|c|c|}
\hline \multicolumn{2}{|c|}{ Variables } & n & Percentage \\
\hline \multicolumn{4}{|c|}{ Duration of stay } \\
\hline & $<5$ days & 44 & 54 \\
\hline & 5-10 days & 35 & 43 \\
\hline & $>10$ days & 03 & 4 \\
\hline \multicolumn{4}{|c|}{ Duration of ICU } \\
\hline \multirow[t]{3}{*}{ stay } & 1-4 days & 15 & 18 \\
\hline & 5-10 days & 08 & 11 \\
\hline & $>10$ days & 00 & 00 \\
\hline \multicolumn{4}{|c|}{ Hemo-dialysis } \\
\hline & Yes & 03 & 4 \\
\hline & No & 79 & 96 \\
\hline \multirow[t]{2}{*}{$\begin{array}{c}\text { Mechanical } \\
\text { ventilation } \\
\text { required }\end{array}$} & Yes & 12 & 16 \\
\hline & No & 69 & 84 \\
\hline \multirow[t]{3}{*}{$\begin{array}{c}\text { Type of } \\
\text { mechanical } \\
\text { ventilation }\end{array}$} & Non-invasive & 08 & 11 \\
\hline & Invasive & 03 & 04 \\
\hline & Both & 01 & 02 \\
\hline \multicolumn{4}{|l|}{ Medicine used } \\
\hline & Doxycycline Only & 25 & 31 \\
\hline & $\begin{array}{l}\text { Doxycycline } \\
+ \text { Ceftriaxone }\end{array}$ & 13 & 16 \\
\hline & $\begin{array}{l}\text { Doxycycline + } \\
\text { Azithromycin }\end{array}$ & 13 & 16 \\
\hline & Doxycycline + Other & 31 & 37 \\
\hline Mortality & & 03 & 04 \\
\hline
\end{tabular}

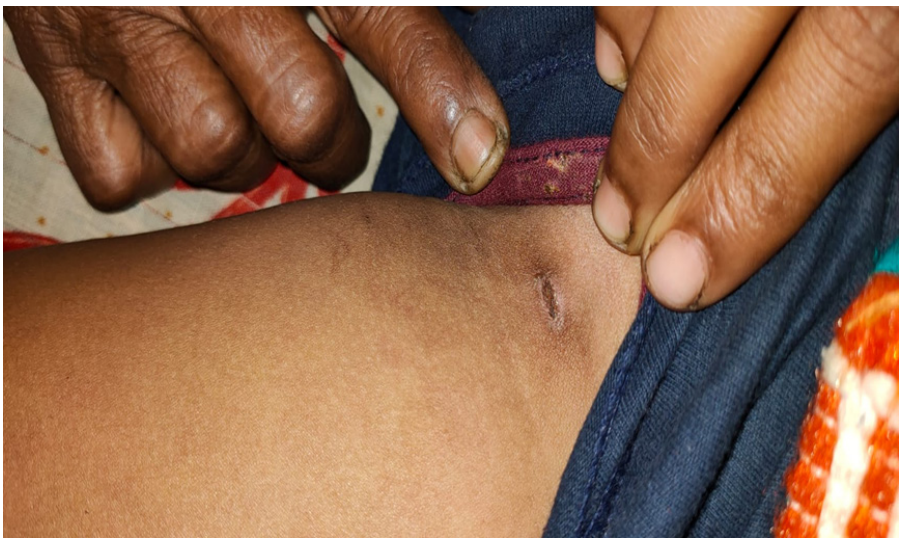

Figure 1: Eschar on the body surface of scrub typhus patient.

dialysis support. The observed mortality was 3 (4\%). ARDS developed among two patients. Two case of sub-acute meningitis also noticed. $31 \%$ patients were treated with only doxycycline. But rest of the patients required another anti-microbial medication as per co-morbid disorders (Table 5).

\section{DISCUSSION}

In this present study we had documented a case series of scrub typhus cases during month of September, 2019 to March 2020 which were quite
Table 4: Distribution of report of investigations of scrub typhus patients ( $\mathrm{n}: \mathbf{8 2}$ )

\begin{tabular}{|c|c|c|}
\hline Variables & $n$ & Percentage \\
\hline $\mathrm{Hb}<11 \mathrm{gm} / \mathrm{dl}$ & 42 & 52 \\
\hline $\mathrm{WBC}<4000 /$ cumm & 04 & 05 \\
\hline WBC>11000/cumm & 31 & 37 \\
\hline $\begin{array}{c}\text { Platelet count }<1 \mathrm{lak} / \\
\text { cumm }\end{array}$ & 21 & 25 \\
\hline Increased bilirubin & 12 & 14 \\
\hline $\begin{array}{l}\text { Increased urea/ } \\
\text { creatinine }\end{array}$ & 08 & 10 \\
\hline $\begin{array}{c}\text { Elevated transaminase } \\
\text { levels }\end{array}$ & 19 & 23 \\
\hline Elevated AST & 29 & 36 \\
\hline Elevated ALT & 31 & 37 \\
\hline Typhoid IgM positive & 10 & 12 \\
\hline HCV IgM positive & 00 & 00 \\
\hline HbsAG & 00 & 00 \\
\hline HIV positive & 00 & 00 \\
\hline Malaria & 01 & 02 \\
\hline Dengue & 04 & 05 \\
\hline LRTI/URTI & 22 & 27 \\
\hline UTI & 10 & 12 \\
\hline Plural Effusion & 16 & 20 \\
\hline
\end{tabular}

unusual time of occurrence. The extended rainy season and also sporadic unusual rain in winter might be an explanation. Demographic analysis of our study revealed a mixed picture regarding occupation of participants where most active age group was found more vulnerable for scrub typhus. This similar observation was observed in Sinha et al. Madi et al. and Takhar et al. study. ${ }^{4-6}$ Females account for $54 \%$ and most of them were housewives. Our hospital serves in an area of migrating workers where women usually look after the agricultural works during harvesting time. This could be a possible explanation of this trend. Almost same observation observed in Takhar et al. study in Rajasthan. ${ }^{4}$ While Rajoor et al. reported more men to be affected in his place. ${ }^{7}$

Only two patients had classical Escher or rash in this current study. In Indian context we differ from classical description of scrub typhus with the absence of Escher. This may be due to re-exposure, variation of strains or resistance by indigenous population. Our study supports this finding with other study ${ }^{8}$ regarding the absence or less presence of Escher/rashes among South-East Asian scrub typhus patients.

We have also noted positivity of dengue serology in four of our patients and presence of malaria co-infection in one patient which are very much endemic in this area. We had experienced several outbreak of dengue fever for last two to three years which constitutes the major portion of acute febrile illness. Initial presentation of fever, myalgia, tiredness and paucity of rashes makes the initial differential diagnosis very difficult. A significant overlap of presentation and resurgence of scrub typhus in background of dengue endemicity may partly be explained with common behavioral and seasonal pattern. An epidemiological investigation is Needed to be implement to establish the connections. Few studies mentioned presence of co-infection due to common host and environmental factors. ${ }^{9}$ Identification of co-infection is very important, as treatment differs significantly for dengue, malaria and scrub typhus. National guideline for dengue fever management discourages use of 
antibiotics in dengue fever cases. However, application of antibiotic in early phase of scrub typhus can reduce the mortality. So, it is necessary to include scrub typhus serology test as routine blood test for all AFI patients for this area.Perhaps, diversity of presentation apart from fever and lack of uniformity are the hallmark of scrub typhus presentation. $16 \%$ of our participants presented with altered sensorium which is much less than other reported studies. ${ }^{4}$ Headache, weakness, nausea were most common presenting complains after fever which were non-specific in nature but similar with Peesapati et al. study. ${ }^{10}$ Breathlessness and cough were present in $30 \%$ and $29 \%$ of patients which were observed in severe condition among hemoptysis patients. Our study points towards more respiratory symptoms comparing other reported studies. $20 \%$ of our patients showed radiological evidence of plural effusion which was higher than mostly reported studies. Lymphadenopathy and hepatospleenomegaly were present in $07 \%$ and $21 \%$ in our study respectively which was similar to other studies. ${ }^{4,5}$ One study findings have suggested that the presence of generalized lymphadenopathy indicates a late presentation and a worse outcome of scrub typhus cases. ${ }^{11}$ Percentage of patient with thrombocytopenia is another conspicuous different picture in this study. We noted only $25 \%$ patients with thrombocytopenia in this study. Apart from thrombocytopenia, abnormalities in liver and renal functions in our study matches with other reported in similar studies. ${ }^{4,10}$ Only Two patients admitted with subacute meningitis and one of them expired after longtime management at Intensive Care Unit (ICU). 9 (11\%) patients admitted in emergency with circulatory collapse whereas 12 patients were put on mechanical ventilation. Acute Respiratory Distress Syndrome (ARDS) develops in two patients which was much lower than previously reported., ${ }^{42}$ Both ARDS patients succumbs to death and one patient meet the similar fate after developing acute renal failure. Though the incidence of ARDS and Acute Kidney Injury (AKI) were less than other reported but they stands for most common cause of mortality like similar observational studies. ${ }^{4}$ We observed a low mortality rate $(4 \%)$, which was lower than previously reported 7 to $30 \%{ }^{10,13}$ Facility of tertiary care and increasing awareness among local medical fraternity regarding the disease may be an explanation apart from lower virulence of virus or indigenous resistance as host or environment factor. Most of our patients respond with recommended antibiotic without any adverse reactions which is inspiring in terms of application of complicated second line or third line managements.

\section{CONCLUSION}

With wide spread clinical suspicion of dengue or other fever as etiology of Acute Febrile Illness (AFI) we suggest early screening for scrub typhus as the treatment option for this area can reduce the mortality due to scrub typhus.

\section{ACKNOWLEDGEMENT}

We sincerely thanks to the Dr. Sonali Ghosh, Junior Resident, Department of Medicine, Monmohini Multi-specialty Hospital, Murshidabad for the kind cooperation extended during the course of the study and also acknowledge cooperation of all patients.

\section{CONFLICT OF INTEREST}

The authors declare that there is no conflict of interest.

\section{ABBREVIATIONS}

AFI: Acute febrile illness; AKI: Acute kidney Injury; ALT: Alanine Aminotransferase; ARDS: Acute respiratory distress syndrome; AST: Aspartate Aminotransferase; CBC: complete blood count; Hb\%: Hemoglobin \%; HCV: Hepatitis C Virus; HIV-AIDS: Human Immunodeficiency Virus - acquired Immunodeficiency syndrome; ICU: Intensive care unit; IgM: Immunoglobulin M; PTB: Pulmonary tuberculosis; RTI: Respiratory tract infection; UTI: Urinary tract infection; WBC: White blood cell.

\section{REFERENCES}

1. Watt G, Parola P. Scrub typhus and tropical rickettsioses. Curr Opin Infect Dis. 2003;16(5):429-36.

2. Chakraborty S, Sarma N. Scrub Typhus: An Emerging Threat. Indian J Dermatol. 2017;62(5):478-85. doi:10.4103/ijd.IJD_388_17

3. Jain P, Prakash S, Tripathi PK, et al. Emergence of Orientia tsutsugamushi as an important cause of Acute Encephalitis Syndrome in India. PLoS Negl Trop Dis. 2018;12(3):e0006346. Published 2018 Mar 28. doi:10.1371/journal. pntd.0006346

4. Takhar RP, Bunkar ML, Arya S, Mirdha N, Mohd A. Scrub typhus: A prospective, observational study during an outbreak in Rajasthan, India. Natl Med J India. 2017;30(2):69-72.

5. Sinha P, Gupta S, Dawra R, Rijhawan P. Recent outbreak of scrub typhus in north western part of India. Indian J Med Microbiol. 2014;32(3):247-50.

6. Madi D, Achappa B, Chakrapani M, Pavan MR, Narayanan S, Yadlapati S, et al. Scrub typhus, a reemerging zoonosis: An Indian case series. Asian J Med Sci. 2014;5(3):108-11.

7. Rajoor UG, Gundikeri SK, Sindhur JC, Dhananjaya M. Scrub typhus in adults in a teaching hospital in north Karnataka, 2011-2012. Ann Trop Med Public Health. 2013;6(6):614-7.

8. Kundavaram AP, Jonathan AJ, Nathaniel SD, Varghese GM. Eschar in scrub typhus: A valuable clue to the diagnosis. J Postgrad Med. 2013;59(3):177-8.

9. Sapkota S, Bhandari S, Sapkota S, Hamal R. Dengue and Scrub Typhus Coinfection in a Patient Presenting with Febrile Illness. Case Reports. 2017;3. https://doi.org/10.1155/2017/6214083

10. Peesapati N, Lakkapragada R, Sunitha S, Sivaram PV. Clinical manifestations and complications of scrub typhus: A hospital-based study from North Andhra. Astrocyte. 2015;2(3):116-20.

11. Mahajan SK, Kashyap R, Kanga A, Sharma V, Prasher BS, Pal LS. Relevance of Weil-Felix test in diagnosis of scrub typhus in India. J Assoc Physicians India. 2006;54:619-21.

12. Varghese GM, Trowbridge P, Janardhanan J, Thomas K, Peter JV, Mathews P, et al. Clinical profile and improving mortality trend of scrub typhus in south India. Int J Infect Dis. 2014;23:39-43.

13. Pandey D, Sharma B, Chauhan V, Mokta J, Verma BS, Thakur S. ARDS complicating scrub typhus in sub-Himalayan region. J Assoc Physicians India. 2006;54:812-3. 